\title{
Successful treatment of out-of-hospital cardiopulmonary arrest due to streptococcal toxic shock syndrome - effectiveness of extracorporeal membrane oxygenation and the rapid antigen group $A$ streptococcus test: a case report
}

Yukio Mizuguchi, Norimasa Taniguchi and Akihiko Takahashi

\begin{abstract}
Background: Streptococcal toxic shock syndrome caused by Streptococcus pyogenes, a group A streptococcus, infection is a rare condition that rapidly progresses to multiple organ failure, shock, and death. It is thus important to promptly establish a diagnosis, provide hemodynamic support, and initiate appropriate antibiotics therapy.

Case presentation: A 70-year-old Asian man presented with ventricular fibrillation. Extracorporeal membrane oxygenation was initiated 20 minutes after admission after unsuccessful conventional cardiopulmonary resuscitation including five attempts of electrical cardioversion. On the sixth attempt, a sinus rhythm was obtained. A physical examination revealed a large abscess in his right gluteal region, and computed tomography showed a large low-density area in the right gluteus maximus. Blood examination revealed elevated levels of inflammatory markers, hepatic enzymes, creatinine, and creatinine kinase. Transthoracic echocardiography demonstrated diffuse hypokinesis with an ejection fraction of $25 \%$. A subsequent coronary angiography revealed normal findings. Therefore, we diagnosed our patient as having septic shock and conducted surgical drainage. A rapid antigen group A streptococcus test yielded positive results, which necessitated treatment comprising benzylpenicillin and clindamycin. He was successfully weaned from extracorporeal membrane oxygenation and continuous hemodiafiltration 4 days later and ventilation 9 days later; he was later transferred to another hospital to receive a skin graft.

Conclusions: Our case report is the first to demonstrate the successful treatment of cardiac arrest caused by streptococcal toxic shock syndrome via extracorporeal membrane oxygenation and prompt initiation of antibiotic therapy. The rapid antigen group A streptococcus test may be an effective approach to promptly diagnose streptococcal toxic shock syndrome caused by group A streptococcus infection.
\end{abstract}

Keywords: Streptococcal toxic shock syndrome, Cardiopulmonary arrest, Extracorporeal membrane oxygenation, Rapid antigen group A streptococcus test

\footnotetext{
* Correspondence: yukiomizuguchi@gmail.com

Cardiovascular Section, Sakurakai Takahashi Hospital, 5-18-1 Oikecho,

Suma-ku, Kobe, Hyogo 654-0026, Japan
}

(c) The Author(s). 2018 Open Access This article is distributed under the terms of the Creative Commons Attribution 4.0 International License (http://creativecommons.org/licenses/by/4.0/), which permits unrestricted use, distribution, and reproduction in any medium, provided you give appropriate credit to the original author(s) and the source, provide a link to the Creative Commons license, and indicate if changes were made. The Creative Commons Public Domain Dedication waiver (http://creativecommons.org/publicdomain/zero/1.0/) applies to the data made available in this article, unless otherwise stated. 


\section{Background}

Streptococcal toxic shock syndrome (STSS) caused by Streptococcus pyogenes, a group A streptococcus (GAS), infection is an uncommon but serious illness that rapidly progresses to multiple organ failure, shock, and death. Therefore, it is important to promptly establish a diagnosis, provide hemodynamic support, and initiate appropriate antibiotics therapy. There are multiple prior reports of the use of extracorporeal membrane oxygenation (ECMO) in treatment of toxic shock in adults $[1,2]$. Our case report is the first to demonstrate the successful treatment of cardiac arrest caused by STSS using ECMO and prompt initiation of antibiotic therapy. The rapid antigen GAS test may be an effective approach to promptly diagnose STSS caused by GAS infection.

\section{Case presentation}

A 70-year-old Asian man with ventricular fibrillation, who collapsed suddenly at a public bath, was brought to our hospital via ambulance. He had been prescribed allopurinol to treat gout for 15 years. No other relevant past history was found, including no history of diabetes or heart disease. He was an ex-tobacco smoker and drank one can $(350 \mathrm{~mL})$ of beer daily. ECMO was initiated 20 minutes after unsuccessful conventional resuscitation with five attempts of electrical cardioversion. On the sixth cardioversion attempt, sinus rhythm was achieved. His initial blood investigations showed the following: white blood cells, 70,510 cells $/ \mu \mathrm{L}$; hemoglobin, $14.3 \mathrm{mg} / \mathrm{dL}$; platelets, 433,000 cells/ $\mu \mathrm{L}$; random blood sugar, $174 \mathrm{mg} / \mathrm{dL}$; serum creatinine, $4.90 \mathrm{mg} / \mathrm{dL}$; blood urea nitrogen, $82 \mathrm{mg} / \mathrm{dL}$; serum glutamic-pyruvic transaminase, $76 \mathrm{IU} / \mathrm{L}$; serum glutamic oxaloacetic transaminase, $58 \mathrm{IU} / \mathrm{L}$; creatinine kinase 194 U/L; and serum C-reactive protein, $40.7 \mathrm{mg} / \mathrm{dL}$ (Table 1). Transthoracic echocardiography demonstrated diffuse hypokinesis, and anteroseptal and apical akinesis with impaired left ventricular function and an ejection fraction of 25\%. Emergency coronary angiography revealed normal coronary arteries. On physical examination, a large abscess in his right gluteal region was detected; computed tomography showed a large low-density area in the right gluteus maximus muscle (Fig. 1).

Thus, we diagnosed our patient as having septic shock due to a gluteal abscess and conducted surgical drainage (Fig. 2). Concurrently, a rapid antigen GAS test (Quick Chaser Dip Strep Aं; Mizuho Medy Co., Japan) was performed using a sample obtained from the right gluteal abscess. Positive results were observed within a minute; therefore, antibiotic therapy comprising benzylpenicillin (1200 U/day) and clindamycin (1200 mg/day) was initiated immediately. Five days after admission, the culture of the purulent matter yielded Streptococcus pyogenes; thus, we diagnosed our patient as having STSS based on the criteria [3]. Subsequently, his general condition improved; he was

Table 1 Laboratory data at hospital admission

\begin{tabular}{|c|c|c|c|c|c|}
\hline WBCs & 70,510 & $/ \mu \mathrm{L}$ & Total protein & 7.9 & $\mathrm{~g} / \mathrm{dL}$ \\
\hline Neutrophils & 85.6 & $\%$ & Albumin & 2.7 & $\mathrm{~g} / \mathrm{dL}$ \\
\hline Lymphocytes & 9.1 & $\%$ & $\mathrm{Na}$ & 134 & $\mathrm{mEq} / \mathrm{L}$ \\
\hline Monocytes & 4.9 & $\%$ & K & 5.7 & $\mathrm{mEq} / \mathrm{L}$ \\
\hline Basophils & 0.1 & $\%$ & $\mathrm{Cl}$ & 94 & $\mathrm{mEq} / \mathrm{L}$ \\
\hline Eosinophils & 0.3 & $\%$ & Glucose & 174 & $\mathrm{mg} / \mathrm{dL}$ \\
\hline Hemoglobin & 14.3 & $\mathrm{~g} / \mathrm{dl}$ & $\mathrm{HbA1c}$ & 5.9 & $\%$ \\
\hline \multirow[t]{2}{*}{ Platelets } & 43.3 & $\times 10^{4} / \mu \mathrm{L}$ & & & \\
\hline & & & Arterial blood gas ${ }^{*}$ & & \\
\hline CRP & 40.7 & $\mathrm{mg} / \mathrm{dL}$ & $\mathrm{pH}$ & 6.939 & \\
\hline Total bilirubin & 0.4 & $\mathrm{mg} / \mathrm{dL}$ & $\mathrm{PaCO}_{2}$ & 30.8 & $\mathrm{mmHg}$ \\
\hline AST & 58 & U/L & $\mathrm{PaO}_{2}$ & 66.4 & $\mathrm{mmHg}$ \\
\hline ALT & 76 & U/L & $\mathrm{HCO}_{3}^{-}$ & 6.5 & $\mathrm{mmol} / \mathrm{L}$ \\
\hline LDH & 340 & U/L & $\mathrm{BE}$ & -25.1 & $\mathrm{mmol} / \mathrm{L}$ \\
\hline ALP & 525 & $\mathrm{U} / \mathrm{L}$ & & & \\
\hline үGTP & 66 & U/L & & & \\
\hline CK & 194 & $\mathrm{U} / \mathrm{L}$ & & & \\
\hline Blood urea nitrogen & 82 & $\mathrm{mg} / \mathrm{dL}$ & & & \\
\hline Creatinine & 4.9 & $\mathrm{mg} / \mathrm{dL}$ & & & \\
\hline
\end{tabular}

${ }^{*}$ Arterial blood gas was obtained at $10 \mathrm{~L}$ /minute of oxygen via a face mask

$\gamma$-GTP gamma-glutamyl transpeptidase, ALP alkaline phosphatase, $A L T$ alanine aminotransferase, AST aspartate aminotransferase, $B E$ base excess, $C K$ creatine kinase, $C R P$ C-reactive protein, $\mathrm{HbA1c}$ glycated hemoglobin, $\mathrm{HCO}_{3}{ }^{-}$hydrogen carbonate, $\mathrm{LDH}$ lactate dehydrogenase, $\mathrm{PaCO} \mathrm{O}_{2}$ partial pressure of carbon dioxide in arterial blood, $\mathrm{PaO}_{2}$ partial pressure of oxygen in arterial blood, WBC white blood cell count 


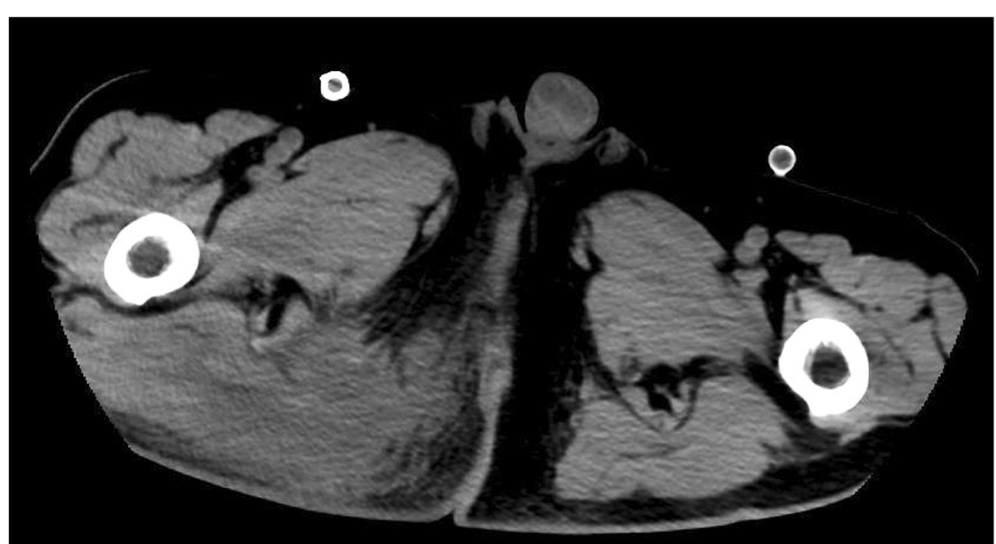

Fig. 1 Computed tomography image of the pelvis showing a large low-density area in the right gluteus maximus muscle

successfully weaned from ECMO and continuous hemodiafiltration on day 4 and successfully weaned from ventilation on day 9. The intravenous administration of antibiotics was continued until day 37 since the initiation of therapy. He was discharged after receiving a skin graft on day 83 (Fig. 3). He had no clinical problem at 6 months after hospital discharge.

\section{Discussion}

Here we reported a case of out-of-hospital cardiac arrest (OHCA) due to septic shock in a 70-year-old Asian man. To the best of our knowledge, this is the first case report to highlight the effectiveness of ECMO on cardiac arrest caused by rapidly progressing STSS. GAS is the most common and frequent causative pathogen of acute pharyngitis, accounting for $10-30 \%$ of cases in children and $5-10 \%$ of cases in adults [4]. However, streptococcal infections are also known to occasionally progress to STSS on rare occasions, in which patients show rapidly worsening clinical conditions and very poor prognoses. A

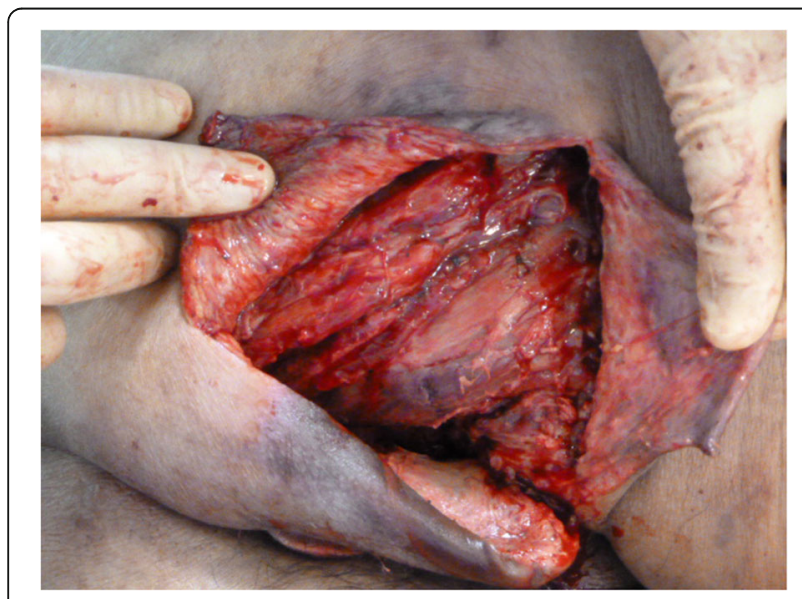

Fig. 2 Surgical drainage of the abscess in the right gluteus maximus muscle retrospective study involving 3566 case-patients with severe Streptococcus pyogenes infection, in which 698 (20\%) patients died within 30 days of culture-positive specimens being obtained, indicated that the survival probability was lowest among patients in whom STSS developed: $26 \%$ of patients with STSS died of septic shock within a day of specimen collection [5]. The utility of ECMO in adults with sepsis remains controversial. In the current case, the patient presented with cardiac arrest, which is resistant to conventional resuscitation; therefore, ECMO was introduced promptly. Although there is a paucity of data supporting the use of ECMO in this spectrum of pathologic conditions, several recent reports have suggested that ECMO can become a valuable therapeutic option for patients with refractory cardiovascular dysfunction, especially when introduced promptly after developing septic shock. A recent retrospective analysis of 151 adult patients with sepsis receiving ECMO claimed that worse outcomes were significantly associated with longer door-to-ECMO times, because delayed rescue leads to irreversible multiorgan failure [6]. Moreover, another study showed that the development of shock beyond 30.5 hours before ECMO initiation was associated with $0 \%$ survival. However, even after successful weaning from ECMO, the prognosis is reported to be poor. That study also reported that among $40.6 \%$ of the patients who were successfully weaned from ECMO, only half $(21.9 \%)$ survived the refractory septic shock [7].

One of the possible explanations for such poor prognoses after successful weaning from ECMO is the delay in the identification of the pathogenic bacteria and the following treatment. A significant disadvantage of culturing a sample is the delay of 1-2 days to obtain results. This delay may cause initiation of inappropriate antibiotic therapy and could be fatal, especially in STSS owing to the rapid progression. Further, indiscriminate use of antibiotics may result in unnecessary adverse reactions, antibiotic resistance, and increased health care costs. Recently, 


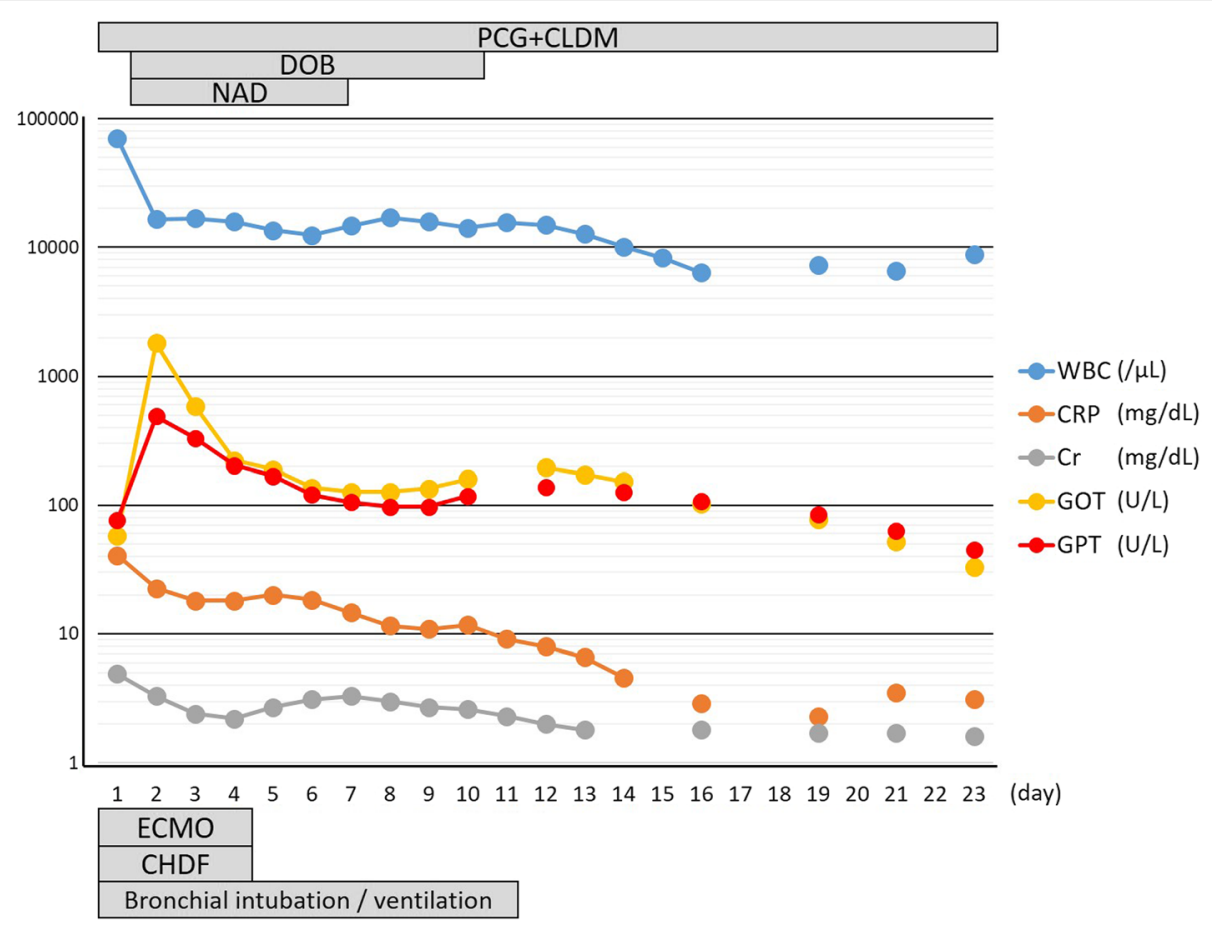

Fig. 3 Clinical course with laboratory and treatment data. CHDF continuous hemodiafiltration, CLDM clindamycin, Cr creatinine, CRP C-reactive protein, DOB dobutamine, ECMO extracorporeal membrane oxygenation, GOT glutamic oxaloacetic transaminase, GPT glutamic-pyruvic transaminase, NAD noradrenaline, $P C G$ penicillin $G, W B C$ white blood cells

high sensitivity-based and specificity-based optical immunoassay technologies for detecting GAS antigen have become available [8-10], in which the results can be obtained within 5-10 minutes. This could allow for prompt treatment of patients with STSS with the appropriate antibiotic and reduce the risk for overuse of antibiotic treatment in uncertain situations while culture results are pending. Early treatment may lead to more rapid improvement of the patient's general condition, as seen in the current case.

\section{Conclusions}

Our case report is the first to demonstrate the successful treatment of OHCA caused by STSS via ECMO and prompt initiation of antibiotic therapy. The findings of this case demonstrated that the rapid antigen GAS test, usually used for the diagnosis of GAS pharyngitis, was very effective to promptly diagnose STSS caused by GAS infection. Emergency physicians who encounter patients OHCA with septic shock should consider the possibility of GAS infection and therefore order a rapid antigen GAS test.

\section{Key summary points}

- We reported a case of OHCA due to septic shock in a 70-year-old Asian man. To the best of our knowledge, this is the first case report to highlight the effectiveness of ECMO on cardiac arrest caused by rapidly progressing STSS.

- The utility of ECMO in adults with sepsis remains controversial. In the current case, the patient presented with cardiac arrest, which is resistant to conventional resuscitation; therefore, ECMO was introduced promptly.

- The rapid antigen GAS test, usually used for the diagnosis of GAS pharyngitis, was very effective to promptly diagnose necrotizing fasciitis and STSS caused by GAS infection.

\section{Funding}

This work was not supported financially or otherwise.

Availability of data and materials

Owing to ethical restrictions, the raw data underlying this study are available upon request from the corresponding author.

\section{Authors' contributions}

All named authors meet the International Committee of Medical Journal Editors (ICMJE) criteria for authorship for this manuscript, take responsibility for the integrity of the work as a whole, and have given final approval for the version to be published. YM, NT, and AT wrote the paper. All authors read and approved the final manuscript.

\section{Ethics approval and consent to participate}

This study was performed in accordance with the Declaration of Helsinki and was approved by the Ethics Committee of Sakurakai Takahashi Hospital. 


\section{Consent for publication}

Written informed consent was obtained from the patient for publication of this case report and any accompanying images. A copy of the written consent is available for review by the Editor-in-Chief of this journal.

\section{Competing interests}

The authors declare that they have no competing interests.

\section{Publisher's Note}

Springer Nature remains neutral with regard to jurisdictional claims in published maps and institutional affiliations.

Received: 2 April 2018 Accepted: 24 July 2018

Published online: 01 September 2018

\section{References}

1. Gabel E, Gudzenko V, Cruz D, et al. Successful use of extracorporeal membrane oxygenation in an adult patient with toxic shock-induced heart failure. J Intensive Care Med. 2015;30:115-8.

2. Imaeda T, Nakada TA, Abe R, et al. Veno-arterial extracorporeal membrane oxygenation for Streptococcus pyogenes toxic shock syndrome in pregnancy. J Artif Organs. 2016;19:200-3.

3. Centers for Disease Control and Prevention. Streptococcal toxic shock syndrome Case Definition. 2010. http://wwwn.cdc.gov/nndss/conditions/ streptococcal-toxic-shock-syndrome/case-definition/2010/. Accessed 17 Dec 2017.

4. Leung AK, Kellner JD. Group A beta-hemolytic streptococcal pharyngitis in children. Adv Ther. 2004;21:277-87.

5. Lamagni TL, Neal S, Keshishian C, et al. Predictors of death after severe Streptococcus pyogenes infection. Emerg Infect Dis. 2009;15:1304-7.

6. Cheng A, Sun HY, Tsai MS, et al. Predictors of survival in adults undergoing extracorporeal membrane oxygenation with severe infections. J Thorac Cardiovasc Surg. 2016;152:1526-36.e1.

7. Park TK, Yang JH, Jeon $\mathrm{K}$, et al. Extracorporeal membrane oxygenation for refractory septic shock in adults. Eur J Cardiothorac Surg. 2015;47:e68-74.

8. Baker DM, Cooper RM, Rhodes C, Weymouth LA, Dalton HP. Superiority of conventional culture technique over rapid detection of group A Streptococcus by optical immunoassay. Diagn Microbiol Infect Dis. 1995;21:61-4.

9. Fries SM. Diagnosis of group a streptococcal pharyngitis in a private clinic: comparative evaluation of an optical immunoassay method and culture. J Pediatr. 1995;126:933-6.

10. Harris R, Paine D, Wittler R, Bruhn F. Impact on empiric treatment of group A streptococcal pharyngitis using an optical immunoassay. Clin Pediatr (Phila). 1995:34:122-7.

Ready to submit your research? Choose BMC and benefit from:

- fast, convenient online submission

- thorough peer review by experienced researchers in your field

- rapid publication on acceptance

- support for research data, including large and complex data types

- gold Open Access which fosters wider collaboration and increased citations

- maximum visibility for your research: over $100 \mathrm{M}$ website views per year

At $\mathrm{BMC}$, research is always in progress.

Learn more biomedcentral.com/submissions 